\title{
05
}

\section{Размеры скачков и уровни деформации металлов}

\author{
(C) В.В. Шпейзман
}

Физико-технический институт им. А.Ф. Иоффе РАН, Санкт-Петербург, Россия

E-mail: shpeizm.v@mail.ioffe.ru

Поступило в Редакцию 6 февраля 2018 г.

Предлагается характеризовать уровни деформации величиной ее скачков, которые можно наблюдать при точном измерении скорости деформации в экспериментах с постоянной или заданной по определенному закону нагрузкой. С помощью прецизионной интерферометрической методики измерена скорость и рассчитаны скачки деформации меди, свинца и олова в микро- и нанометровом диапазонах. Показана корреляция размера скачков с величиной вектора Бюргерса дислокаций в металлах и сделаны предположения о коллективах дислокаций, участвующих в формировании скачка деформации.

DOI: 10.21883/PJTF.2018.15.46444.17241

Многоуровневый характер деформации отмечается во многих исследованиях (см., например, [1-4]). Как правило, понятие „много“ сводится к макро- и микроуровням, к которым в некоторых случаях добавляются мезо- и наноуровни. Неопределенность такого подхода очевидна из-за отсутствия четких границ перехода от одного уровня к другому и различия в структурных характеристиках деформации на разных уровнях. В [5] было предложено определять уровни по величине скачков деформации, которые, как показано в [5-7], всегда наблюдаются при прецизионных измерениях скорости деформации. С помощью разработанной ранее интерференционной методики измерения скорости и величины деформации для различных по природе материалов (металлов, полимеров, композитов) при одноосном нагружении были обнаружены скачки деформации, которые можно описать несколькими характерными размерами изменения длины образца $\Delta l$. Именно этими размерами было предложено определять уровень деформации, причем существовала определенная иерархия скачков, согласно которой скачки каждого последующего уровня включали в себя скачки предыдущего 
уровня. В первых работах этого цикла были рассмотрены микрометровые скачки и для разных материалов и условий деформации были выделены один-три характерных размера, или уровня деформации [8]. В монокристаллах $\mathrm{LiF}$ с различным содержанием $\mathrm{Mg}$ один из уровней (скачков) совпадал со средним расстоянием между примесями. В металлах наибольший размер скачка близок к размеру зерна, а наименьший коррелирует с величиной вектора Бюргерса дислокаций $b$ [6]. В дальнейшем в связи с развитием методики измерений и обработки результатов появилась возможность оценить нанометровые скачки, вследствие чего было получено пять-шесть уровней деформации с размерами скачков от единиц нанометров до десятков микрометров [5].

В настоящей работе проведено измерение микро- и нанометровых скачков деформации ряда поликристаллических металлов и проанализирована связь величины скачков на начальной стадии деформации с величиной вектора Бюргерса дислокаций как в микро-, так и в нанометровом диапазоне. При этом предполагалось, что в рассматриваемых случаях основным механизмом деформации является самосогласованное движение групп дислокаций с характерными размерами, равными величине скачка деформации. В отличие от ранних работ [6-8] экспериментальной базой для определения средних величин микрометровых скачков служили не единицы, а десятки и более измерений. Нанометровые скачки деформации металлов определены впервые.

Образцы меди (99.98 wt.\%), свинца (99.98 wt.\%) и олова (99.98 wt.\%) диаметром $3 \mathrm{~mm}$ и высотой $6 \mathrm{~mm}$ испытывались в режиме ползучести на сжатие при постоянном напряжении и комнатной температуре. Используемая методика измерения величины и скорости деформации основана на эффекте изменения частоты света, отраженного от изменяющего длину образца (эффект Доплера). В результате интерференции первичного и отраженного лучей лазера получаются низкочастотные биения (рис. 1), частота которых определяет скорость деформации, а число биений - ее величину. Указанная методика позволяет определять скорость и величину деформации с шагом по изменению длины образца $\Delta l_{0}=0.325 \mathrm{~nm}$ при частоте дискретизации (частоте следования точек на интерферограмме) до $10 \mathrm{kHz}\left(\Delta l_{0}=\lambda / 2\right.$, где $\lambda-$ длина волны лазера, используемого в установке). Специально разработанное программное обеспечение позволяло производить сбор, обработку и хранение информации, получаемой в эксперименте, в режиме online [7]. Также обработка экспериментальных данных проводилась с применением ПО MATLAB и Origin9.0.

6 Письма в ЖТФ, 2018, том 44, вып. 15 


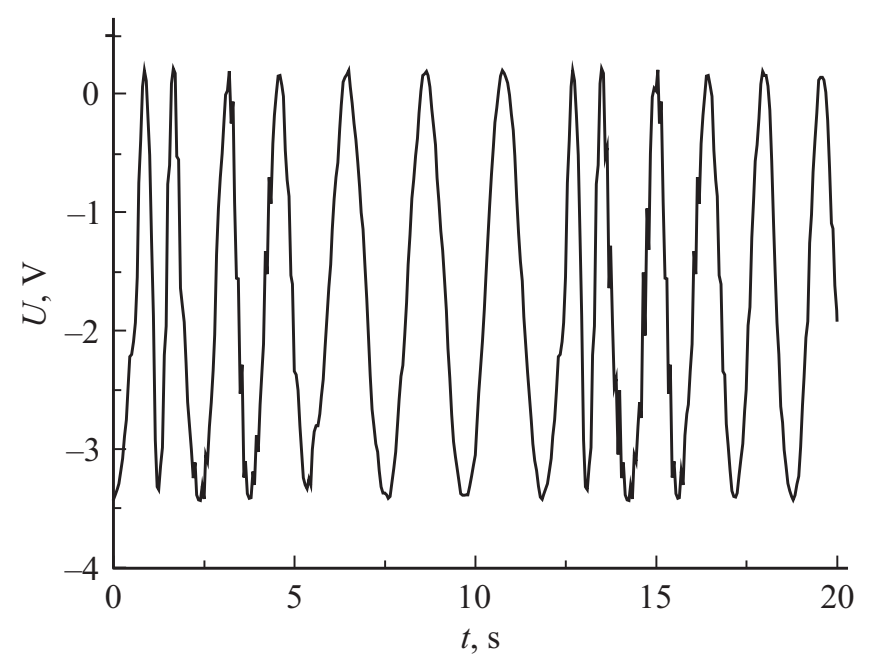

Рис. 1. Участок интерферограммы, показывающий периодичность изменения скорости деформации меди.

Рис. 1 демонстрирует неравномерность изменения скорости в процессе деформации. Отклонения величины скорости деформации от ее закономерного изменения, за которое принималась усредненная зависимость скорости от времени, указывают на скачкообразный характер деформации. За „скачок“ деформации $L$ принимается средняя величина абсолютной деформации $\Delta l$ (изменения длины образца без учета его знака) между близкими по величине скачками скорости. Микрометровые скачки деформации рассчитывались по зависимости $\Delta \dot{\varepsilon} / \dot{\varepsilon}(\Delta l)$, где $\Delta \dot{\varepsilon}-$ отклонение экспериментальной величины относительной скорости от ее значения на усредненной кривой, $\Delta l-$ изменение длины образца.

Величина нанометровых скачков оценивалась по отклонению формы одиночных биений на интерферограмме от стандартной. При этом использовался тот же принцип, что и для микрометровых скачков, однако вместо отклонения скорости бралась величина отклонения сигнала $\Delta U / U_{0}$, где $U_{0}$ - амплитуда биения. Для каждого материала произвольным образом выбиралось несколько одиночных биений, которые аппроксимировались зависимостью $U=U_{0} \sin \left(\omega\left(t-t_{0}\right)\right)$, где $\omega-$

Письма в ЖТФ, 2018, том 44, вып. 15 
частота расчетного сигнала, а $t_{0}$ - время, соответствующее нулевому значению сигнала.

Величина скорости деформации в случае ее оценки по начальной длине образца для всех исследованных материалов была равна $10^{-6}-10^{-5} \mathrm{~s}^{-1}$.

На рис. 2, $а$ в качестве примера приведен участок зависимости $\Delta \dot{\varepsilon} / \dot{\varepsilon}(\Delta l)$ для свинца. Аналогичные зависимости были получены для меди и олова. Уточненные результаты для микрометровых скачков деформации исследованных металлов сравнивались с полученными в [6], размеры нанометровых скачков деформации металлов в области малых деформаций ранее не были известны. Как видно из рис. 2,a, колебания скорости деформации следуют через близкие по величине деформации образца, которые формируют микрометровые скачки. Расчет средней величины скачка деформации $L$ по 30 скачкам, показанным на рис. $2, a$, дает $L=1.17 \pm 0.09 \mu \mathrm{m}$, что близко к приведенному в [6] значению $L=1.1 \mu \mathrm{m}$. Для меди и олова были получены соответственно $L=1.07 \pm 0.11$ и $1.33 \pm 0.15 \mu \mathrm{m}$. Эти значения также близки к приведенным в [6]. На рис. 2, $a$ можно заметить также два больших микрометровых скачка с размерами $\sim 10-20 \mu \mathrm{m}$ (см. усредненную кривую).

Нанометровые скачки малого размера при деформации свинца показаны на рис. $2, b$. На отрезке $\Delta l \sim 100 \mathrm{~nm}$ можно видеть 14 скачков с близкой величиной деформации $L$. Точное измерение среднего значения и среднеквадратичной ошибки дает $L=7.1 \pm 0.5 \mathrm{~nm}$. Так же как и в случае микрометровых скачков деформации, можно заметить, что малые скачки образуют скачок более крупного $(\sim 80 \mathrm{~nm})$ размера. Для меди и олова были получены соответственно $L=3.9 \pm 0.4$ и $9.6 \pm 0.7 \mathrm{~nm}$.

В [6] для ряда поликристаллических металлов и монокристаллов $\mathrm{LiF}$ была установлена линейная зависимость между размерами малых микрометровых скачков деформации и величиной вектора Бюргерса дислокаций $b$. Полученные в настоящей работе результаты позволяют уточнить эту зависимость для микрометровых скачков и проверить, соблюдается ли она для нанометровых скачков. На рис. 3 показаны новые результаты и данные, приведенные ранее в [6]. Как видно, линейная зависимость между $L$ и $b$ соблюдается как для микрометровых, так и для нанометровых скачков. Зависимости $L(b)$ можно описать выражением $L=630+1310 b$ для микрометровых скачков и

$6^{*}$ Письма в ЖТФ, 2018, том 44, вып. 15 

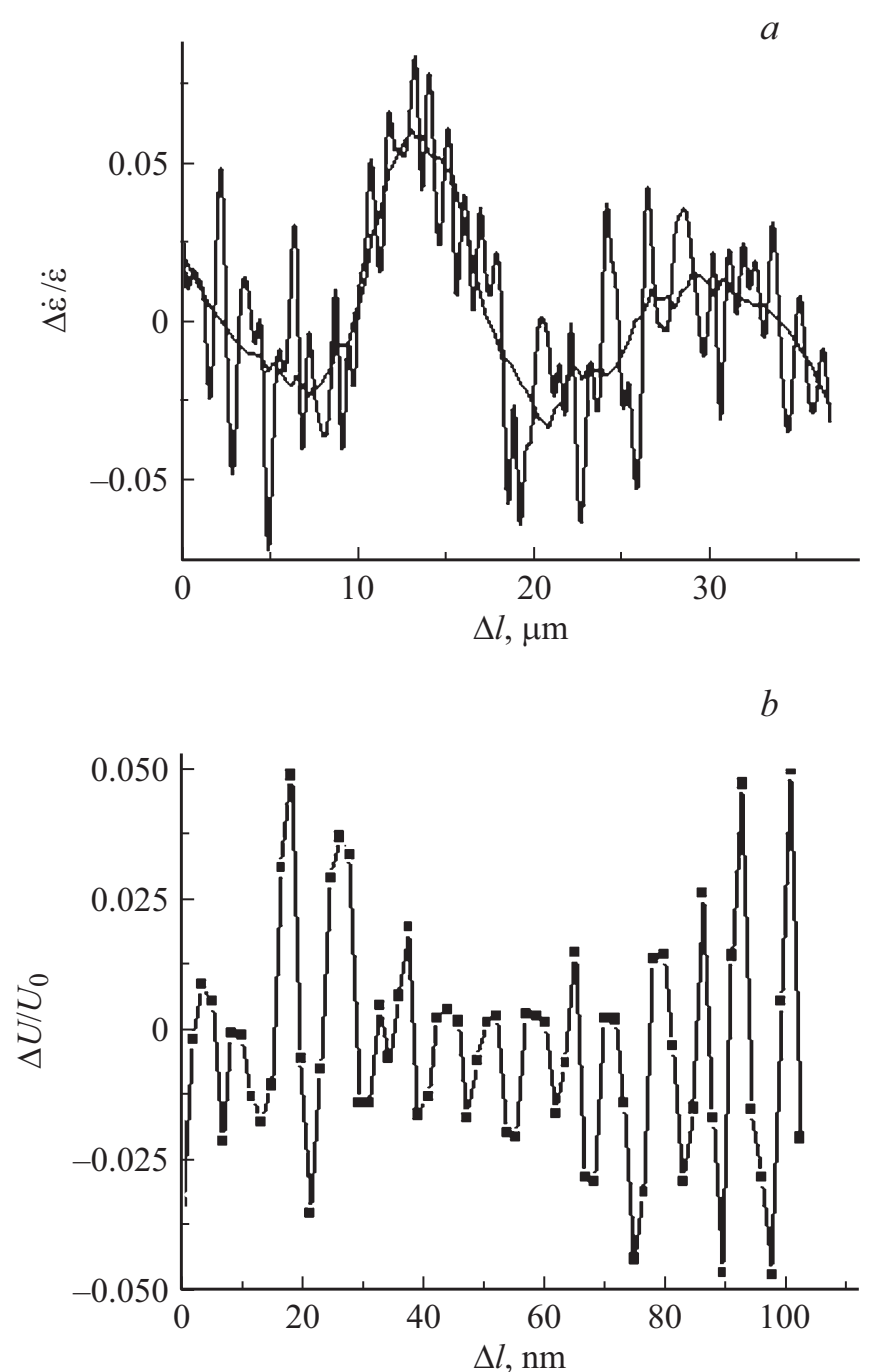

Рис. 2. Микрометровые $(a)$ и нанометровые $(b)$ скачки деформации при одноосном сжатии образцов свинца. 


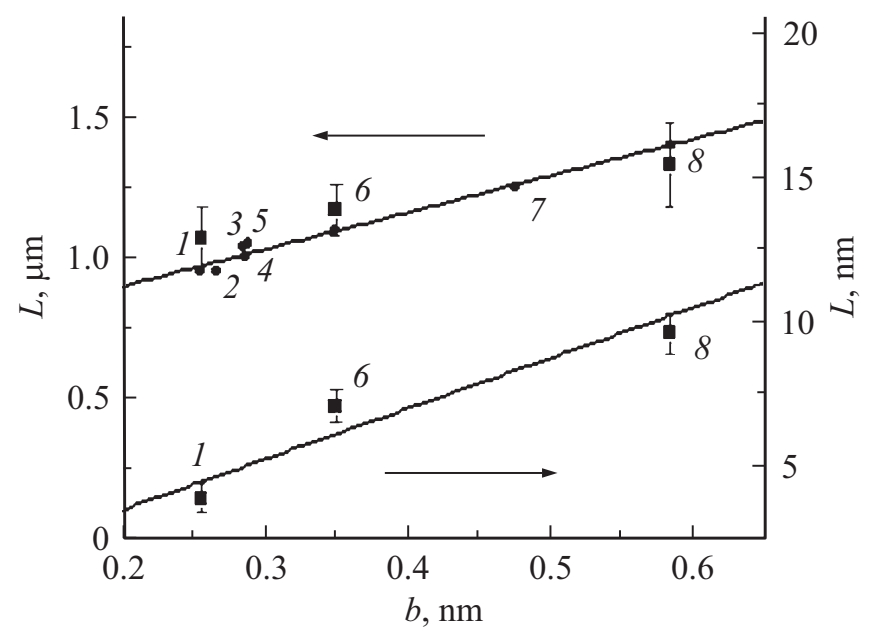

Рис. 3. Зависимости размера микрометровых (вверху) и нанометровых (внизу) скачков деформации от величины вектора Бюргерса дислокаций в различных материалах. $1-\mathrm{Cu}, 2-\mathrm{Zn}, 3-\mathrm{Al}, 4-\mathrm{LiF}, 5-\mathrm{Ag}, 6-\mathrm{Pb}, 7-\mathrm{Sb}$, 8 - Sn. Данные, показанные кружками, взяты из работы [6].

выражением $L=0.01+17.5 b$ для нанометровых, если в обоих случаях $L$ и $b$ выразить в нанометрах. Поскольку вторая зависимость начинается практически в нулевой точке, это означает, что достаточно 17-18 дислокациям сделать один „шаг“ на величину $b$, чтобы образовать нанометровый скачок. Еще меньшее их количество требуется, если рассматривать двойные и более крупные „шаги“. Тот факт, что указанные значения одинаковы для разных металлов, свидетельствует в пользу предположения об одинаковых устойчивых структурных элементах, определяющих процесс деформации, что приближает нас к пониманию элементарного акта деформации металлов.

Микрометровые скачки в разных металлах содержат разное число нанометровых скачков (от $\sim 140$ в $\mathrm{Sn}$ до $\sim 270$ в $\mathrm{Cu}$ ), и в них участвуют, если по-прежнему считать только одиночные „шаги“, соответственно от $\sim 2500$ до $\sim 4800$ дислокаций. Сделанные оценки являются весьма приближенными, но они подчеркивают коллективный характер самосогласованного движения дислокаций, обусловливающего скачкообразную деформацию материалов.

Письма в ЖТФ, 2018, том 44, вып. 15 


\section{Список литературы}

[1] Панин В.Е., Лихачев В.А., Гриняев Ю.В. Структурные уровни деформации твердых тел. Новосибирск: Наука, 1985. 230 с.

[2] Зуев Л.Б., Данилов В.И., Баранникова С.А. Физика макролокализации пластического течения. Новосибирск: Наука, 2008. 327 с.

[3] Владимиров В.И. Физическая природа разрушения. М: Металлургия, 1984. $280 \mathrm{c}$.

[4] Конева Н.А., Козлов Э.В. // Изв. вузов. Физика. 1990. № 2. С. 89-106.

[5] Шиейзман В.В., Песчанская Н.Н. // ФТТ. 2011. Т. 53. В. 6. С. 1169-1174.

[6] Песчанская Н.Н., Шпейзман В.В., Синани А.Б., Смирнов Б.И. // ФТТ. 2004. T. 46. B. 11. C. 1991-1995.

[7] Шиейзман В.В., Песчанская Н.Н., Якушев П.Н., Смолянский А.С., Шведов А.С., Черемисов В.Г. // ФТТ. 2010. Т. 52. В. 2. С. 248-252.

[8] Песчанская Н.Н., Христова Ю. // ФТТ. 2006. Т. 48. В. 10. С. 1786-1790. 